ARTICLE

Received 21 Dec 2013 | Accepted 10 Jun 2014 | Published 11 Jul $2014 \quad$ DOl: 10.1038/ncomms5350

\title{
A distinct sodium channel voltage-sensor locus determines insect selectivity of the spider toxin Dcla
}

\author{
Niraj S. Bende, Sławomir Dziemborowicz ${ }^{2}$, Mehdi Mobli ${ }^{3}$, Volker Herzig ${ }^{1}$, John Gilchrist ${ }^{4}$,
} Jordan Wagner ${ }^{4}$, Graham M. Nicholson², Glenn F. King ${ }^{1}$ \& Frank Bosmans ${ }^{4,5}$

$\beta$-Diguetoxin-Dcla (Dcla) is a toxin from the desert bush spider Diguetia canities that incapacitates insects at concentrations that are non-toxic to mammals. Dcla promotes opening of German cockroach voltage-gated sodium $\left(\mathrm{Na}_{v}\right)$ channels $\left(\mathrm{BgNa}_{v} 1\right)$, whereas human $\mathrm{Na}_{v}$ channels are insensitive. Here, by transplanting commonly targeted S3b-S4 paddle motifs within $\mathrm{BgNa}_{\mathrm{v}} 1$ voltage sensors into $\mathrm{K}_{\mathrm{v}} 2.1$, we find that Dcla interacts with the domain II voltage sensor. In contrast, Dcla has little effect on sodium currents mediated by $\mathrm{PaNa}_{\mathrm{v}} 1$ channels from the American cockroach even though their domain II paddle motifs are identical. When exploring regions responsible for $\mathrm{PaNa}_{\mathrm{v}} 1$ resistance to Dcla, we identified two residues within the $\mathrm{BgNa}_{\mathrm{v}} 1$ domain II S1-S2 loop that when mutated to their $\mathrm{PaNa}_{\mathrm{v}} 1$ counterparts drastically reduce toxin susceptibility. Overall, our results reveal a distinct region within insect $\mathrm{Na}_{v}$ channels that helps determine Dcla sensitivity, a concept that will be valuable for the design of insect-selective insecticides.

\footnotetext{
${ }^{1}$ Institute for Molecular Bioscience, The University of Queensland, St Lucia, Queensland QLD 4072, Australia. ${ }^{2}$ School of Medical and Molecular Biosciences, University of Technology, Sydney, New South Wales 2007, Australia. ${ }^{3}$ Centre for Advanced Imaging, The University of Queensland, St Lucia, Queensland QLD 4072, Australia. ${ }^{4}$ Department of Physiology, School of Medicine, Johns Hopkins University, Baltimore, Maryland 21205, USA. ${ }^{5}$ Solomon H. Snyder Department of Neuroscience, School of Medicine, Johns Hopkins University, Baltimore, Maryland 21205, USA. Correspondence and requests for materials should be addressed to G.F.K. (email: glenn.king@imb.uq.edu.au) or to F.B. (email: frankbosmans@jhmi.edu).
} 
nsect voltage-gated sodium $\left(\mathrm{Na}_{\mathrm{v}}\right)$ channels share a common architecture with their mammalian orthologues ${ }^{1}$. The poreforming subunit consists of four connected domains (DI-IV), each with six transmembrane segments (S1-S6). These homologous, but not identical, domains each contain a voltage sensor (S1-S4) and a portion of the pore through which $\mathrm{Na}^{+}$can diffuse (S5-S6) ${ }^{2}$. While they have yet to be identified in insect $\mathrm{Na}_{\mathrm{v}}$ channels, each voltage-sensing domain within mammalian and bacterial $\mathrm{Na}_{\mathrm{v}}$ channels contains an S3b-S4 helix-turn-helix motif, the voltage-sensor paddle, which drives voltage-sensor activation $^{3-6}$. Aside from its vital role in channel gating, the paddle motif is also an important pharmacological target, as peptide toxins interact with this region to modify channel opening ${ }^{3,4,7}$. Insect $\mathrm{Na}_{\mathrm{v}}$ channels likely possess similar motifs since residue substitutions in homologous regions can abolish channel susceptibility to toxins found in animal venoms ${ }^{1}$. Even though voltage-sensing domains are extensively targeted by naturally occurring peptides, commercially available insecticides such as pyrethroids and oxadiazines typically interact with the channel pore region or intracellular linker between S4 and S5 to disrupt opening or closing (that is, gating) ${ }^{8,9}$. However, insects have responded to this threat by mutating residues at strategic locations within the channel that result in a reduced sensitivity to these compounds ${ }^{9}$. Moreover, the conserved nature of the $\mathrm{Na}_{\mathrm{v}}$ channel pore throughout the animal kingdom often leads to undesired biological activity of insecticides in beneficial insect orders or mammals ${ }^{8-10}$. Since the amino acid composition of voltage-sensing domains varies considerably between related $\mathrm{Na}_{\mathrm{v}}$ channel isoforms, these regions may replace the pore as a target for designing insecticides with a higher degree of phyletic selectivity, an intriguing notion that has yet to be fully explored.
$\mathrm{Na}_{\mathrm{v}}$ channels have been governing electrical excitability in a wide range of organisms for millions of years, even before the development of neurons $s^{2,11}$. Thus, it is not surprising that ancient organisms such as spiders developed an arsenal of toxins geared towards incapacitating prey by modulating $\mathrm{Na}_{\mathrm{v}}$ channel function ${ }^{12-15}$. One intriguing specimen is the desert bush spider (Diguetia canities) whose habitat spans the Southwestern deserts of the United States ${ }^{16,17}$. The venom of this relatively unexplored primitive weaving spider contains a 57-residue peptide known as DTX9.2 (or $\beta$-diguetoxin-Dcla ${ }^{18}$, hereafter Dcla; Fig. 1a), one of the most potent insect-selective neurotoxins found in arthropod venoms ${ }^{19}$. Although its precise molecular target has yet to be elucidated, neurophysiological studies on housefly larvae revealed excitation of sensory and neuromuscular preparations on Dcla application that could be blocked by the $\mathrm{Na}_{\mathrm{v}}$ channel-blocking compound tetrodotoxin ${ }^{20}$.

Here, we show that Dcla potently promotes opening of the German cockroach $\mathrm{Na}_{\mathrm{v}}$ channel $\mathrm{BgNa}_{\mathrm{v}} 1$ (ref. 21) by interacting with the paddle motif in domain II. Surprisingly, Dcla has little effect on $\mathrm{PaNa}_{\mathrm{v}} 1$-expressing neurons isolated from the American cockroach (Periplaneta americana) ${ }^{22}$, even though the toxinbinding site is identical in these two cockroach channels. By exploring regions responsible for the remarkable insect-family specificity of Dcla, we uncovered an important role for the domain II S1-S2 loop in determining $\mathrm{PaNa}_{\mathrm{v}} 1$ resistance to Dcla. Together with the unique solution structure of Dcla, our results provide a proof of concept that toxins-and by extension small molecules-can selectively target insect $\mathrm{Na}_{\mathrm{v}}$ channels by interacting with their voltage-sensing domains, thus facilitating the development of new insecticides.

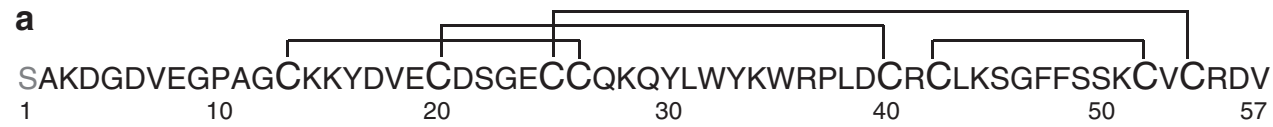

b

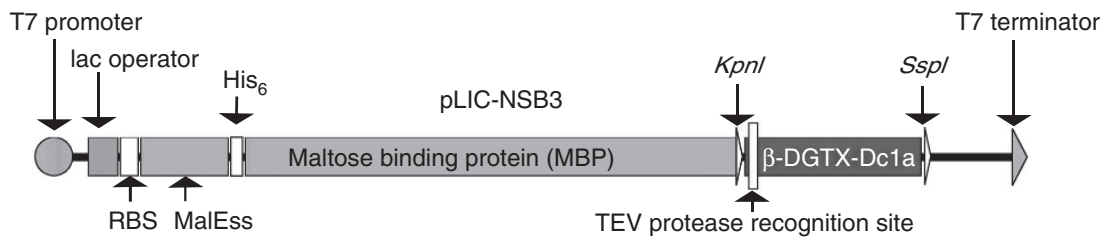

C
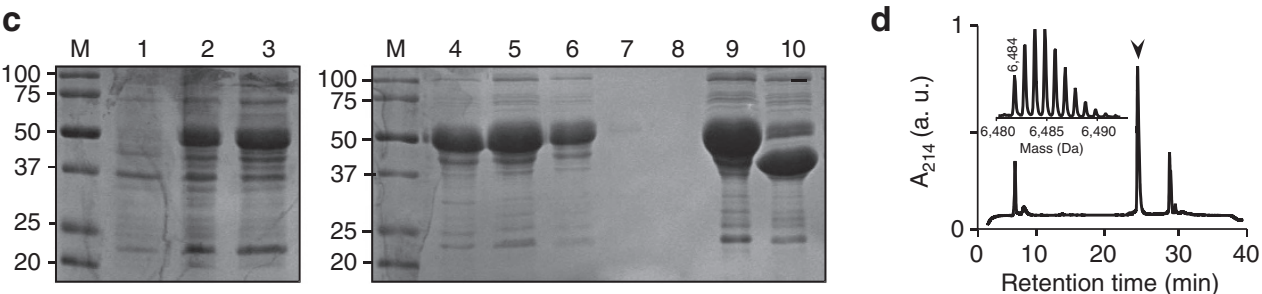

Figure 1 | Recombinant production of Dc1a. (a) Primary structure of rDc1a. The non-native N-terminal Ser residue that is a vestige of the TEV protease cleavage site used for recombinant toxin production is highlighted in grey. Disulphide bridge connectivity is shown above the sequence. (b) Schematic representation of the pLIC-NSB3 vector used for periplasmic expression of rDc1a. The coding region includes a MalE signal sequence (MalEsS) for periplasmic export, a His 6 affinity tag, an MBP fusion tag and a codon-optimized gene encoding rDcla, with a TEV protease recognition site inserted between the MBP and toxin-coding regions. The locations of key elements of the vector are shown, including the ribosome-binding site (RBS).

(c) SDS-polyacrylamide gel electrophoresis gels illustrating different steps in the purification of rDcla. Lanes contain: $M$, molecular weight markers; lane 1 ,

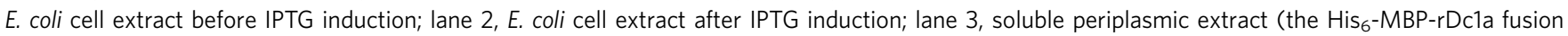
protein is evident at $\sim 50 \mathrm{kDa}$ ); lane 4, Ni-NTA beads after loading the cell lysate; lane 5, eluate-1 from washing Ni-NTA resin with 600 mM imidazole; lane 6, elute-2 from washing Ni-NTA resin with $600 \mathrm{mM}$ imidazole; lane 7, eluate-3 from washing Ni-NTA resin with $600 \mathrm{mM}$ imidazole; lane 8 , Ni-NTA beads after elution-3; lane 9, fusion protein sample before TEV protease cleavage; lane 10, fusion protein sample after TEV protease cleavage showing almost complete cleavage of fusion protein to $\mathrm{His}_{6}-\mathrm{MBP}$. (d) RP-HPLC chromatogram showing the final step in the purification of rDcla. The arrow head denotes the peak corresponding to correctly folded recombinant rDcla. Inset is a MALDI-TOF MS spectrum showing the $[M+\mathrm{H}]^{+}$ion for the purified recombinant toxin (obs. $=6,484 \mathrm{Da}$; calc. $=6,485.39 \mathrm{Da}$ ). 


\section{Results}

Production of recombinant Dcla. We first produced recombinant Dcla peptide ( $\mathrm{rDcla}$ ) using a novel approach that addresses the challenge of correctly folding disulphide-rich spider toxins in $E$. coli ${ }^{23}$. To this end, we created an isopropyl- $\beta$-Dthiogalactopyranoside (IPTG)-inducible construct (Fig. 1b) that allows for export of a $\mathrm{His}_{6}$-MBP-Dcla fusion protein to the $E$. coli periplasm, where the enzymes involved in disulphidebond formation are located ${ }^{23}$. On recovery from the soluble cell fraction, the fusion protein was purified using nickel affinity chromatography (Fig. 1c). Subsequent cleavage and chromatographic purification yielded a single major disulphidebond isomer with a purity of $>98 \%$ as assessed by SDSpolyacrylamide gel electrophoresis and matrix-assisted laser desorption/ionization time-of-flight (MALDI-TOF) mass spectrometry (Fig. 1d). Note that, with four disulphide bonds, there are 105 possible disulphide-bond isomers of rDcla. Overall, the final yield was $\sim 1.1 \mathrm{mg}$ of toxin per litre of culture. Since native Dcla was unavailable to us, we confirmed the insecticidal activity of rDcla by injection into the blowfly Lucilia cuprina and the housefly Musca domestica, which yielded $\mathrm{LD}_{50}$ values of $231 \pm 32 \mathrm{pmolg}^{-1}$ and $493 \pm 52 \mathrm{pmolg}^{-1}$, respectively $(n=3)$ (Supplementary Fig. 1). We therefore conclude that $\mathrm{rDcla}$ has a similar lethality to agricultural pests when compared with native toxin ${ }^{19}$.
Solution structure of rDcla. The development of an efficient bacterial expression system allowed us to produce uniformly ${ }^{13} \mathrm{C} /{ }^{15} \mathrm{~N}$-labelled $\mathrm{rDcla}$ protein for structure determination using heteronuclear NMR. ${ }^{1} \mathrm{H}_{\mathrm{N}},{ }^{15} \mathrm{~N},{ }^{13} \mathrm{C}_{\alpha},{ }^{13} \mathrm{C}_{\beta}$, and ${ }^{13} \mathrm{C}^{\prime}$ resonance assignments for the toxin were obtained from analysis of amide-proton strips in three-dimensional (3D) HNCACB, $\mathrm{CBCA}(\mathrm{CO}) \mathrm{NH}$, and $\mathrm{HNCO}$ spectra. Sidechain ${ }^{1} \mathrm{H}$ and ${ }^{13} \mathrm{C}$ chemical shifts were obtained using a four-dimensional (4D) $\mathrm{HCC}(\mathrm{CO}) \mathrm{NH}-\mathrm{TOCSY}$ experiment, which has the advantage of providing sidechain ${ }^{1} \mathrm{H}-{ }^{13} \mathrm{C}$ connectivities ${ }^{24}$. Complete chemical shift assignments have been deposited in BioMagResBank (Accession Number 19666). CYANA was used for automated NOESY assignment and structure calculation ${ }^{25}$. The disulphidebond pattern $(1-4,2-5,3-8,6-7)$ was unambiguously determined from preliminary structures calculated without disulphide-bond restraints ${ }^{26}$ and is identical to the framework predicted in the UniProtKB entry for Dcla (P49126). Of the 200 structures that were calculated from random starting conformations, 20 conformers with high stereochemical quality (as judged by MolProbity ${ }^{27}$ ) were selected to represent the solution structure of rDcla (Fig. 2a). Atomic coordinates for the final ensemble of 20 structures are available from the Protein Data Bank (PDB; Accession Number 2MI5).

Statistics highlighting the high precision and stereochemical quality of the ensemble of rDcla structures are shown in a

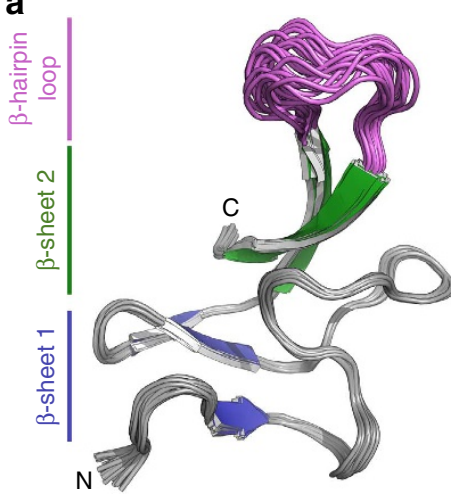

C

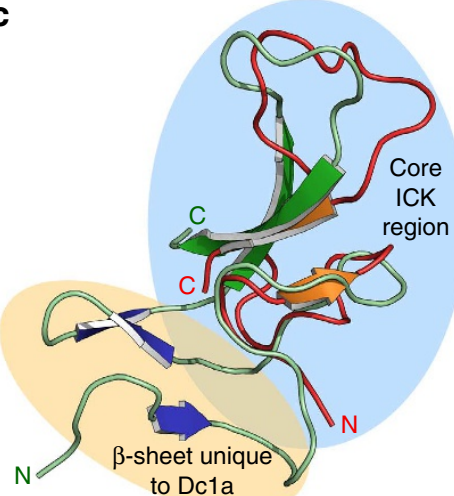

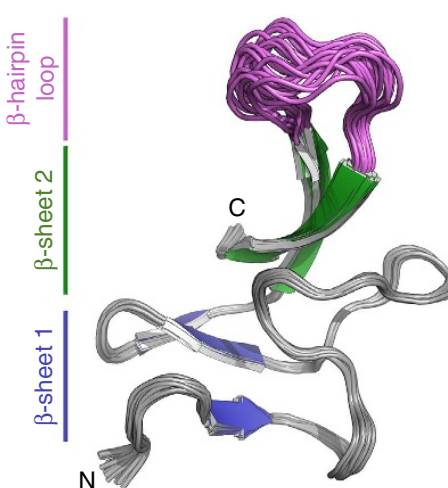

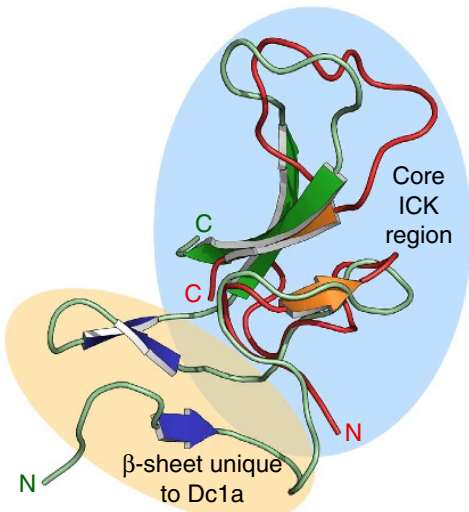

b

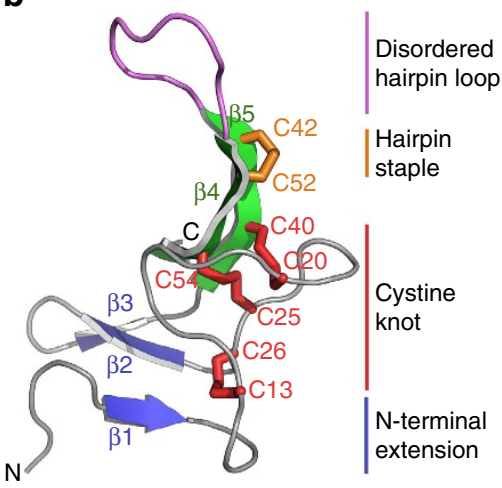

d

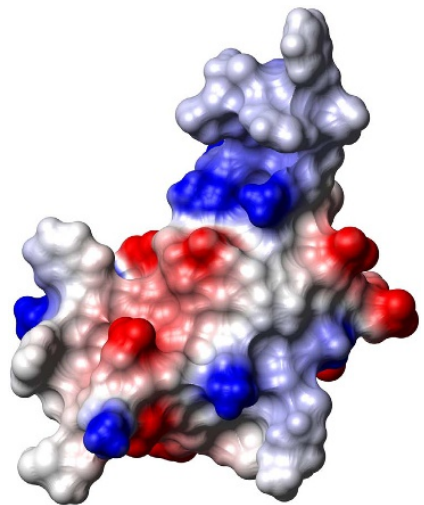

Figure 2 I NMR solution structure of rDc1a. (a) Stereo view of the ensemble of 20 rDcla structures. The structures are overlaid over the backbone atoms of residues 2-42 and 52-56 in order to highlight the disordered nature of the hairpin loop (residues 43-51, purple) relative to the well-structured ICK region of the toxin. The $\mathrm{N}$ and $\mathrm{C}$ termini are labelled and the $\beta$-strands that form the $\mathrm{N}$ - and $\mathrm{C}$-terminal $\beta$-sheets are coloured blue and green, respectively. (b) Ribbon representation of rDcla highlighting the five $\beta$ - strands ( $\beta 1-\beta 5$ ) and four disulphide bonds. The three disulphide bonds that form the ICK motif are shown in red while the fourth disulphide that staples the base of the disordered $\beta 4-\beta 5$ hairpin loop is highlighted in orange. The $\beta$-strands and disordered hairpin loop are coloured as in a. (c) Stereo view of the structures of As1a, a typical knottin peptide ${ }^{30}$, overlaid with rDc1a. The two structures were overlaid for optimal superposition over their core ICK regions (28 residues; region highlighted in cyan) using the CLICK server ${ }^{70}$. Note that the $\mathrm{N}$-terminal $\beta$-sheet in rDcla is quite distinct from the region of structural overlap. (d) Electrostatic surface potential of rDcla with positive and negative charges shown in blue and red, respectively. The molecular orientation is the same as in panels $\mathbf{a}$ and $\mathbf{c}$. 
Supplementary Table 1. The average MolProbity score of 1.24 places the ensemble in the 99th percentile relative to all other structures ranked by MolProbity. The high stereochemical quality of the ensemble stems from a complete absence of bad close contacts and an excellent Ramachandran plot quality ( $>99 \%$ of residues in the most favoured region). The structural ensemble is also highly precise with backbone and heavy-atom root-meansquare deviation (r.m.s.d.) values over all the structural ordered regions (residues $3-42,52-56$ ) of $0.27 \pm 0.07 \AA$ and $0.70 \pm 0.11 \AA$, respectively. The ensemble of $\mathrm{rDcla}$ structures ranks as 'very high resolution' based on these measures of precision and stereochemical quality ${ }^{28}$.

Three of the four disulphide bonds in rDcla form a classical inhibitor cysteine knot (ICK) motif in which the Cys13-Cys26 and Cys20-Cys40 disulphide bonds and the intervening sections of the polypeptide backbone form a 23-residue ring that is pierced by the Cys25-Cys54 disulphide bond (Fig. 2b). This ICK motif is commonly found in spider toxins, and this particular scaffold provides these peptides (so-called 'knottins') with an unusually high degree of chemical, thermal and biological stability ${ }^{15}$. However, the structure of rDcla differs markedly from other ICK toxins, and a DALI search ${ }^{29}$ of the PDB returned no structural homologues. First, rDcla contains an additional disulphide bond (Cys42-Cys52) that appears to serve as a molecular staple which limits the flexibility of a disordered serinerich hairpin loop (residues 43-51) (Fig. 2b). Stapled hairpins of this kind have been observed in only a small number of spider toxins ${ }^{30}$. Second, the extended $\mathrm{N}$ terminus of rDcla along with an unusually large loop between Cys26 and Cys40 enables the formation of an amino-terminal ( $\mathrm{N}$-terminal) three-stranded antiparallel $\beta$-sheet that is not found in any other knottin (Fig. 2b,c). The uniqueness of the rDcla structure can readily be seen by comparison with the structure of Asla, a typical spider venom-derived knottin that modulates the activity of insect $\mathrm{Na}_{V}$ channels ${ }^{30}$. The two toxins can be aligned over their core ICK regions with an rmsd of $1.9 \AA$ (Fig. 2 c) consistent with them both being members of the knottin family. However, when aligned over this ICK region, the $\mathrm{N}$-terminal $\beta$-sheet of $\mathrm{rDcla}$ is entirely separate to the region of structural overlap (Fig. 2c). Despite its structural uniqueness, the molecular surface of rDcla contains a relatively uniform distribution of charged residues (Fig. 2d); moreover, there are no distinct clusters of hydrophobic residues that might mediate an interaction with lipid bilayers ${ }^{7,31}$ (Supplementary Movie 1).

rDcla opens the German cockroach $\mathrm{Na}_{\mathrm{v}}$ channel $\mathrm{BgNa}_{\mathbf{v}} 1$. Diguetia spiders are generalist predators and their diet consists of various insects ranging from small ants to sizeable prey such as grasshoppers and cockroaches ${ }^{16,32}$. As such, we decided to test whether $\mathrm{rDcla}$ influences the gating properties of $\mathrm{BgNa}_{\mathrm{v}} 1$, a well-studied $\mathrm{Na}_{\mathrm{v}}$ channel isoform cloned from the German cockroach $^{8,21}$. We functionally expressed $\mathrm{BgNa}_{\mathrm{v}} 1$ in Xenopus oocytes and applied various concentrations of rDcla. At $1 \mu \mathrm{M}$, rDcla produced robust opening of $\mathrm{BgNa}_{\mathrm{v}} 1$ at voltages where the channel is normally closed. This was achieved by a drastic shift in channel activation to more negative potentials $\left(\mathrm{V}_{1 / 2}\right.$ was shifted from $-27.3 \pm 0.2 \mathrm{mV}$ (mean \pm s.e.m.) (slope $4.0 \pm 0.2$ ) to $-49.4 \pm 0.4 \mathrm{mV}$ (slope $3.5 \pm 0.3$ ) in the presence of $1 \mu \mathrm{M}$ rDcla; Fig. 3a) whereas steady-state inactivation (or channel availability) was only slightly affected $\left(\mathrm{V}_{1 / 2}\right.$ was shifted from $-52.2 \pm 0.1 \mathrm{mV}$ to $-55.1 \pm 0.1 \mathrm{mV}$ in the presence of $1 \mu \mathrm{M}$ rDcla; Fig. 3a). The rate of recovery from fast inactivation was also not significantly altered ( $\tau$ is $2.1 \pm 0.1 \mathrm{~ms}$ versus $2.2 \pm 0.1 \mathrm{~ms}$; Fig. 3b). On addition of $1 \mu \mathrm{M}$ rDcla to channels depolarized to $-60 \mathrm{mV}$ every $5 \mathrm{~s}$, sodium currents became rapidly visible as a a

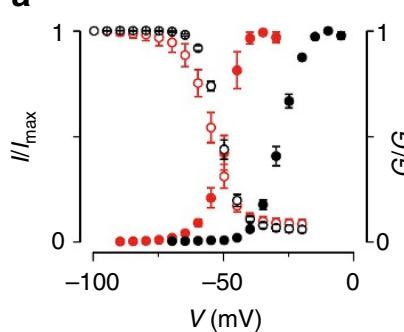

C
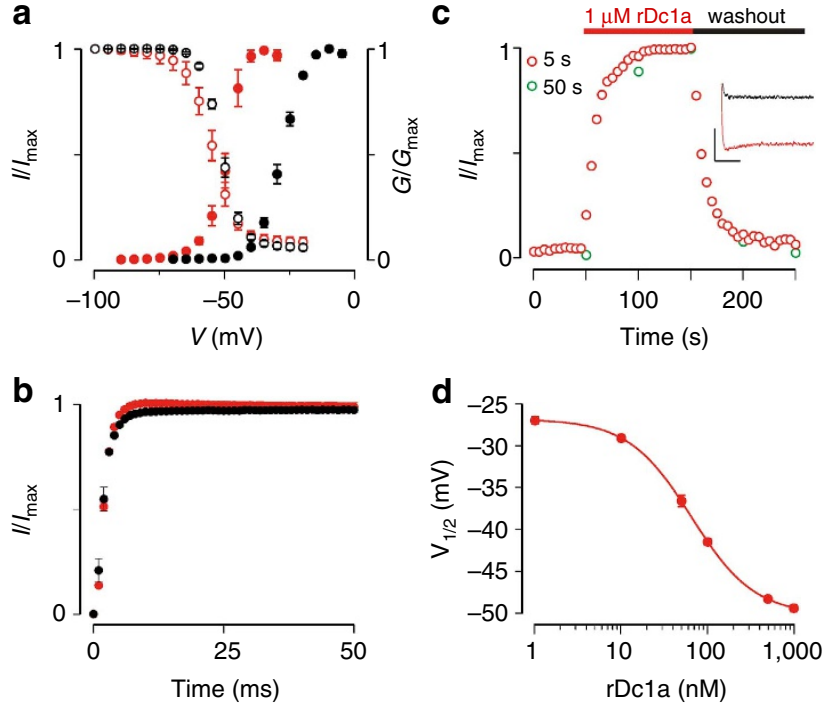

Figure 3 | rDc1a promotes opening of $\mathbf{B g N a}_{\mathbf{v}} \mathbf{1}$ channels. (a) Comparison of the gating properties of $\mathrm{BgNa}_{\mathrm{v}} 1$ before (black), and after (red), addition of $1 \mu \mathrm{M}$ rDcla. Shown are the normalized deduced conductance $(G)$-voltage (filled circles) $\left(G / G_{\max }\right)$ and steady-state inactivation (open circles; $\left.I / I_{\max }\right)$ relationships. Currents were elicited by $5-\mathrm{mV}$ step depolarizations from a holding voltage of $-90 \mathrm{mV}$ or $-100 \mathrm{mV}$, respectively. $n=3-5$, and error bars represent s.e.m. Descriptive values resulting from Boltzmann fits can be found in the Results section. (b) Recovery from fast inactivation of WT $\mathrm{BgNa}_{\mathrm{v}} 1$ before (black), and after (red), addition of $1 \mu \mathrm{M}$ rDcla (red) determined by a double-pulse protocol to $-30 \mathrm{mV}$ with a varying time between pulses $(0-50 \mathrm{~ms})$. Values are reported in the Results section. Data represents $n=4$ experiments, and error bars represent the s.e.m. (c) On addition of $1 \mu \mathrm{M}$ rDcla to channels depolarized to $-60 \mathrm{mV}$ every $5 \mathrm{~s}$ (red open circles) or $50 \mathrm{~s}$ (green open circles; holding voltage was $-100 \mathrm{mV}$ ), BgNav1-mediated sodium currents become rapidly visible. Channels completely recover after toxin washout. Inset shows current trace before (black), and after (red), addition of $1 \mu \mathrm{M}$ rDcla at $-60 \mathrm{mV}(5 \mathrm{~s}$ pulses). Noticeable is the persistent current that appears at this voltage, even in control experiments. Abscissa scale is $10 \mathrm{~ms}$, ordinate scale is $0.3 \mu \mathrm{A}$. (d) Concentration dependence of rDcla-induced current potentiation determined from shifts in the midpoint of channel activation $\left(V_{1 / 2}\right)$. Line represents a fit of the data with the Hill equation resulting in a half-maximal concentration ( $E_{50}$ ) of $65 \pm 1 \mathrm{nM}$ and a slope factor of $1.19 \pm 0.02 ; n=5$ and error bars represent s.e.m.

result of the $-22 \mathrm{mV}$ shift in voltage-dependent opening of $\mathrm{BgNa}_{\mathrm{v}} 1$ (Fig. 3c). Moreover, rDcla similarly affects the channel when voltage-steps to $-60 \mathrm{mV}$ were applied every $50 \mathrm{~s}$, suggesting that the toxin can access its binding site when $\mathrm{BgNa}_{\mathrm{v}} 1$ is in the resting state ${ }^{12}$. Channels completely recovered following washout in toxin-free solution (Fig. 3c). The persistent nature of the emerging current does not stem from the inhibition of fast inactivation by rDcla since wild-type (WT) $\mathrm{BgNa}_{\mathrm{v}} 1$ inherently possesses these characteristics at mildly depolarizing voltages ${ }^{33}$. Fitting the Hill equation to the concentration dependence for toxin-induced current potentiation, as determined by shifts in $\mathrm{V}_{1 / 2}$, yielded an $\mathrm{EC}_{50}$ of $65 \pm 1 \mathrm{nM}$ and a Hill coefficient of $1.19 \pm 0.02$ (Fig. 3d) suggesting that the toxin may interact with only one binding site.

Interestingly, $1 \mu \mathrm{M}$ rDcla did not affect any of the tested vertebrate $\mathrm{Na}_{\mathrm{v}}$ channel isoforms or the hERG channel ${ }^{34}$, a member of the cardiac voltage-gated potassium $\left(\mathrm{K}_{\mathrm{v}}\right)$ channel family and an Food and Drug Administration-mandated screening target for potential off-target drug effects (Supplementary Fig. 2a). These results are consistent with the report that Dcla has no effect in mice when injected 
intraperitoneally or intracerebroventricularly at doses of 4.1 and $1.0 \mathrm{mg} \mathrm{kg}^{-1}$, respectively ${ }^{19}$.

rDcla interacts with the domain II paddle motif in $\mathrm{BgNa}_{\mathrm{v}} 1$. Subsequently, we were interested in identifying the receptor sites for $\mathrm{rDcla}$ within insect $\mathrm{Na}_{\mathrm{v}}$ channels that result in such a profound shift in the voltage dependence of activation. Our experiments with $\mathrm{BgNa}_{\mathrm{v}} 1$ suggest that $\mathrm{rDcla}$ functions as an excitatory toxin to activate insect $\mathrm{Na}_{\mathrm{v}}$ channels at membrane voltages where they are normally closed. Hence, the toxin may interact with $\mathrm{S} 3 \mathrm{~b}-\mathrm{S} 4$ paddle motifs within $\mathrm{BgNa}_{\mathrm{v}} 1$ voltage sensors in a manner analogous to previously described $\beta$-scorpion toxins $s^{3,35,36}$. In order to test this hypothesis, we first needed to establish whether $\mathrm{BgNa}_{\mathrm{v}} 1$ contains paddle motifs with similar functions as in $\mathrm{K}_{\mathrm{v}}$ channels ${ }^{37-39}$ and in mammalian $\mathrm{Na}_{\mathrm{v}}$ channel isoforms where they have been identified $\left(\mathrm{rNa}_{\mathrm{v}} 1.2 \mathrm{a}, \mathrm{rNa}_{\mathrm{v}} 1.4\right.$, $\mathrm{rNa}_{\mathrm{v}} 1.8, \mathrm{rNa}_{\mathrm{v}} 1.9$, and $\left.\mathrm{hNa}_{\mathrm{v}} 1.9\right)^{3,4}$. To this end, we employed a previously reported approach in which specific $\mathrm{S} 3 \mathrm{~b}-\mathrm{S} 4$ regions from each voltage-sensing domain of a $\mathrm{Na}_{v}$ channel were transplanted into homotetrameric $K_{v}$ channels (Fig. 4a) ( $^{3,4,7}$. After several attempts (Fig. 4a), we were able to generate functional chimeras between $\mathrm{BgNa}_{\mathrm{v}} 1$ and $\mathrm{K}_{\mathrm{v}} 2.1$ using known paddle motif boundaries ${ }^{3,4}$ (Fig. 4a,b). All of the constructs contain the crucial basic residues that contribute to gating charge movement in $\mathrm{K}_{\mathrm{v}}$ channels ${ }^{40,41}$, suggesting that each of the four voltage-sensing domains in $\mathrm{BgNa}_{\mathrm{v}} 1$ contain paddle motifs that are capable of sensing membrane voltage changes.

Examination of the conductance-voltage $(G-V)$ relationships for the $\mathrm{BgNa}_{\mathrm{v}} 1 / \mathrm{K}_{\mathrm{v}} 2.1$ chimeras reveals that each of the four voltage-sensor paddles has a distinct effect on the gating properties of $\mathrm{K}_{\mathrm{v}} 2.1$. This was evidenced by marked differences in the midpoints of activation for the $G-V$ relations for the domain I, II and IV constructs which are $\geq 50 \mathrm{mV}, 13 \pm 2 \mathrm{mV}$, and $-9 \pm 2 \mathrm{mV}$, respectively (Fig. 4c). The $G-V$ relationship for the domain III $\mathrm{BgNa}_{\mathrm{v}} 1 / \mathrm{K}_{\mathrm{v}} 2.1$ construct is bimodal, suggesting that the functional coupling between the voltage-sensing domains and the pore has been considerably altered. Although the underlying mechanism is unclear, it is possible that pore opening in this particular chimera may occur when: (1) not all four voltage sensors are fully activated ${ }^{42}$; or (2) each voltage sensor has transferred only a portion of its charge across the hydrophobic septum $^{43-45}$. The latter scenario seems more likely since in the related Shaker $\mathrm{K}_{\mathrm{v}}$ channel, all four voltage sensor need to be in the active position before the pore opens ${ }^{42,46}$. Moreover, intermediate states have also been observed when measuring gating currents of the Shaker $\mathrm{K}_{\mathrm{v}}$ channel in which a mutation immobilized voltagesensor movement between the resting and activated states, thereby shifting the voltage activation of the ionic currents ${ }^{47}$. Finally, it is worth mentioning that the domain III $\mathrm{BgNa}_{\mathrm{v}} 1 / \mathrm{K}_{\mathrm{v}} 2.1$ construct may display multiple open states according to a model that has been described for N-type $\mathrm{Ca}_{\mathrm{v}}$ channels ${ }^{48}$.

Remarkably, domain IV paddle motifs from $\mathrm{rNa}_{\mathrm{v}} 1.2 \mathrm{a}$ and $\mathrm{rNa}_{\mathrm{v}} 1.4$ slow activation kinetics when transplanted into $\mathrm{K}_{\mathrm{v}}$ channels. These observations support the notion that the domain IV paddle motif contributes substantially to the overall rate of voltage-sensor activation ${ }^{3,4}$. To explore whether the domain IV paddle motif serves a similar role in $\mathrm{BgNa}_{\mathrm{v}} 1$, we measured the kinetics of activation and deactivation of the four $\mathrm{BgNa}_{\mathrm{v}} 1$ paddle constructs in response to membrane depolarization and repolarization, respectively. Similar to previously studied chimeric channels, the activation and deactivation kinetics observed for the domain IV construct of $\mathrm{BgNa}_{\mathrm{v}} 1 / \mathrm{K}_{\mathrm{v}} 2.1$ are slower over a wide voltage range when compared with the other domains (Fig. $4 \mathrm{~d}$ ), suggesting that this particular domain may indeed contribute to fast inactivation in insect $\mathrm{Na}_{\mathrm{v}}$ channels ${ }^{49-51}$. We obtained a

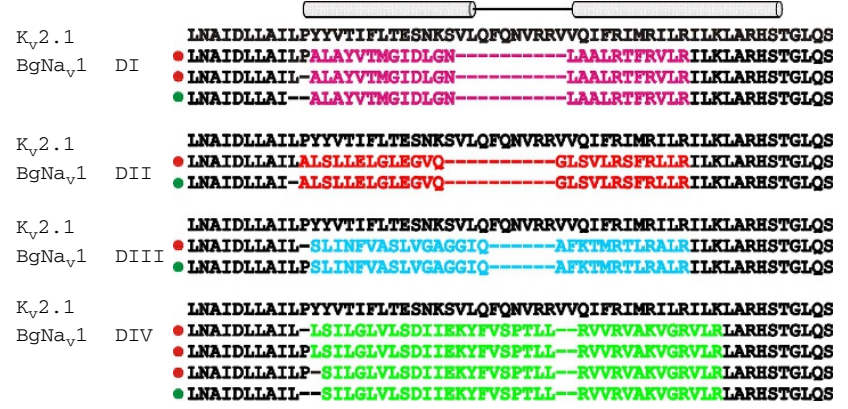

b DI

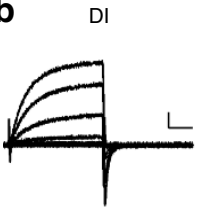

DII

DIII

DIV

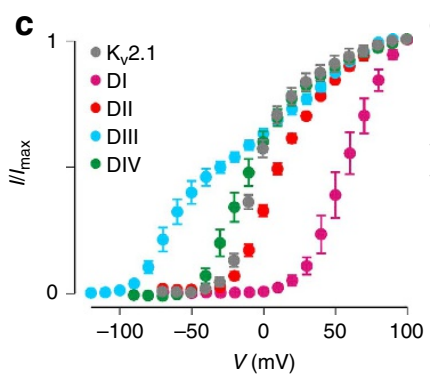

d
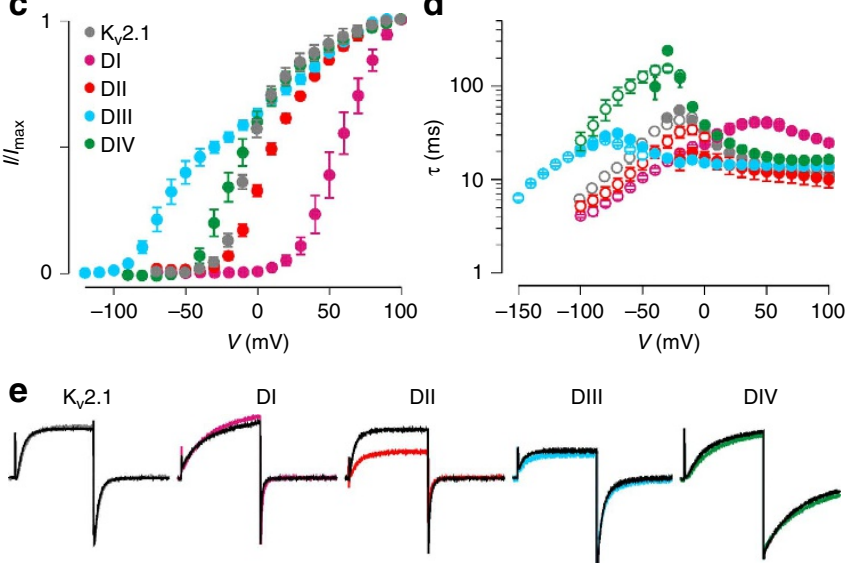

Figure 4 | Transfer of the voltage sensor paddle motifs from $\mathrm{BgNa}_{\mathbf{v}} \mathbf{1}$ to $K_{\mathbf{v}}$ 2.1. (a) Sequence alignment of the paddle region of $K_{v} 2.1$ with the separate S3b-S4 regions of $\mathrm{BgNa}_{\mathrm{v}} 1$ arranged per domain. $\ln \mathrm{BgNa}_{\mathrm{v}} 1$, the paddle motifs are not identical and are therefore coloured differently: purple, domain I paddle (DI); red, domain II paddle (DII); blue, domain III paddle (DIII); green, domain IV paddle (DIV). In $\mathrm{K}_{\mathrm{v}} 2.1$, the paddle motifs are identical and therefore have the same colour (black). Functional chimeras are indicated with a green dot in front of the sequence whereas nonfunctional chimeras are indicated with a red dot. $(\mathbf{b}, \mathbf{c})$ Transfer of the $\mathrm{BgNa}_{\mathrm{v}} 1$ paddle motifs into $\mathrm{K}_{\mathrm{v}}$ 2.1. Families of potassium currents $(\mathbf{b})$ and tail current voltage-activation relationships (c) for each chimeric construct ( $n=6$; error bars represent s.e.m.). Holding voltage was $-90 \mathrm{mV}$ for DI, II, and IV, and $-120 \mathrm{mV}$ for DIII, and the tail voltage was $-60 \mathrm{mV}$

( $-100 \mathrm{mV}$ for DIII). Bars in $\mathbf{b}$ are $1 \mu \mathrm{A}$ and $100 \mathrm{~ms}$. (d) Kinetics of opening and closing for $K_{v} 2.1$ channels containing paddle motifs from the four domains of $\mathrm{BgNa}_{\mathrm{v}}$ 1. Mean time constants $(\tau)$ from single-exponential fits to channel activation (filled circles) and deactivation (open circles) are plotted as a function of the voltage at which the current was recorded. $n=6$, and error bars represent s.e.m. (e) Potassium currents elicited by depolarizations near the foot (less than $1 / 3$ of maximal activation) of the voltage-activation curve (c) for $\mathrm{BgNa}_{\mathrm{v}} 1 / \mathrm{K}_{\mathrm{v}} 2.1$ chimeric constructs. Currents are shown before (black) and following (coloured) addition of $1 \mu \mathrm{M} \mathrm{rDcla}$. rDc1a clearly affects only the DII chimera.

additional evidence for the functional role of the domain IV paddle motif in $\mathrm{BgNa}_{\mathrm{v}} 1$ gating from experiments with BomIV, a classic insect-selective $\alpha$-scorpion toxin from the venom of Buthus occitanus mardochei that inhibits fast inactivation in 
American cockroach neurons ${ }^{52}$. To determine whether BomIV influences $\mathrm{BgNa}_{\mathrm{v}} 1$ in a similar fashion, we applied $10 \mathrm{nM}$ to channel-expressing Xenopus oocytes and observed that the toxin indeed slows down fast inactivation (Supplementary Fig. 2b). Subsequent testing on the $\mathrm{BgNa}_{\mathrm{v}} 1 / \mathrm{K}_{\mathrm{v}} 2.1$ chimeras revealed that BomIV does not affect WT $\mathrm{K}_{\mathrm{v}} 2.1$ or the domain I, II, and III constructs. However, a dramatic toxin-induced inhibition of the domain IV chimera corroborates the importance of this particular voltage-sensing domain in toxin binding and $\mathrm{BgNa}_{\mathrm{v}} 1$ fast inactivation (Supplementary Fig. 2b).

We next investigated whether rDcla modulates the activity of any of the four $\mathrm{BgNa}_{\mathrm{v}} 1 / \mathrm{K}_{\mathrm{v}} 2.1$ paddle chimeras and found that $1 \mu \mathrm{M}$ rDcla exclusively interacts with the domain II construct whereas domains I, III, IV, and WT K 2.1 are unaffected (Fig. 4e, Supplementary Fig. 2c). This result suggests that $\mathrm{rDcla}$ specifically targets the domain II voltage sensor within $\mathrm{BgNa}_{\mathrm{v}} 1$ to influence channel opening.

rDcla distinguishes between cockroach $\mathrm{Na}_{\mathrm{v}} 1$ channels. Since the domain II paddle motif in $\mathrm{BgNa}_{\mathrm{v}} 1$ (ref. 21) is identical to that in $\mathrm{PaNa}_{\mathrm{v}} 1$ (ref. 22), we expected a similar effect of rDcla in whole-cell patch-clamp recordings from American cockroach dorsal unpaired median (DUM) neurons. Surprisingly, $1 \mu \mathrm{M}$ rDcla had little effect on sodium current amplitude or kinetics in DUM neurons as reflected in the threshold, or $\mathrm{V}_{1 / 2}$, of $\mathrm{Na}_{\mathrm{v}}$ channel activation or the $\mathrm{V}_{1 / 2}$ of steady-state inactivation measurements (Supplementary Fig. 3). Furthermore, there were no significant use-dependent effects on sodium current amplitude or kinetics.

Due to the unexpectedly weak effects of $1 \mu \mathrm{M}$ rDcla on voltage-dependent activation of $P$. americana DUM neurons compared with $\mathrm{BgNa}_{\mathrm{v}} 1$ channels from $B$. germanica, acute toxicity assays were expanded to include both cockroach species (Fig. 5a,b). Remarkably, these bioassays revealed lethal toxicity of rDcla in B. germanica compared with only mild, reversible effects in $P$. americana. At doses up to $5 \mathrm{nmol} \mathrm{g}^{-1}, \mathrm{rDcla}$ generated only minor spastic contractions of the abdomen, some shaking and evidence of reduced motor activity in P. americana. Even though these effects were completely reversible, a very small percentage of cockroaches did develop paralysis after $24 \mathrm{~h}(7 \pm 7 \%$ knockdown, $n=3$ ). One explanation for these observations may be toxin binding to a subset of $\mathrm{Na}_{\mathrm{v}}$ channel splice variants ${ }^{53}$ or the presence of endogenous pharmacologically active auxiliary subunits $^{54}$. Conversely, B. germanica underwent dose-dependent flaccid or contractile paralysis, and lethality was observed after $8 \mathrm{~h}$ at all doses tested (Fig. 5a). The $\mathrm{KD}_{50}$ and $\mathrm{LD}_{50}$ values at $24 \mathrm{~h}$ post injection were $3.0 \pm 1.2 \mathrm{nmolg}^{-1}$ and $4.2 \pm 3.4 \mathrm{nmolg}^{-1}$ $(n=3)$, respectively. These observations suggest that residues in regions outside of the domain II paddle motif may underlie the remarkably different sensitivity of $\mathrm{BgNa}_{\mathrm{v}} 1$ and $\mathrm{PaNa}_{\mathrm{v}} 1$ to rDcla.

The S1-S2 loop modulates $\mathrm{Na}_{\mathrm{v}}$ channel sensitivity to $\mathrm{rDcla}$. Sequence alignment of $\mathrm{BgNa}_{\mathrm{v}} 1$ with $\mathrm{PaNa}_{\mathrm{v}} 1$ reveals a highly conserved S1-S4 voltage sensor in domain II with only three amino acid substitutions (Fig. 6a; Supplementary Fig. 4). Of those, two residues in the S1-S2 loop are potentially accessible for a peptide toxin applied from the extracellular environment (His805 and Asp812 in $\mathrm{BgNa}_{\mathrm{v}} 1$ which correspond to a Tyr and Glu in $\mathrm{PaNa}_{\mathrm{v}} 1$, respectively). On mutating these residues in $\mathrm{BgNa}_{\mathrm{v}} 1$ to their $\mathrm{PaNa}_{\mathrm{v}} 1$ counterparts, the resulting $\mathrm{BgNa}_{\mathrm{v}} \mathrm{1}^{\mathrm{YE}}$ construct functionally expressed in Xenopus oocytes with a voltage-dependent activation $\mathrm{V}_{1 / 2}$ of $-41.5 \pm 0.3 \mathrm{mV}$ and a steady-state inactivation $\mathrm{V}_{1 / 2}$ of $-56.4 \pm 0.2 \mathrm{mV}$ (Fig. 6b). Unfortunately, a functional $\mathrm{PaNa}_{\mathrm{v}} 1$ clone was unavailable to undertake gain-of-function experiments. Strikingly, $100 \mathrm{nM}$
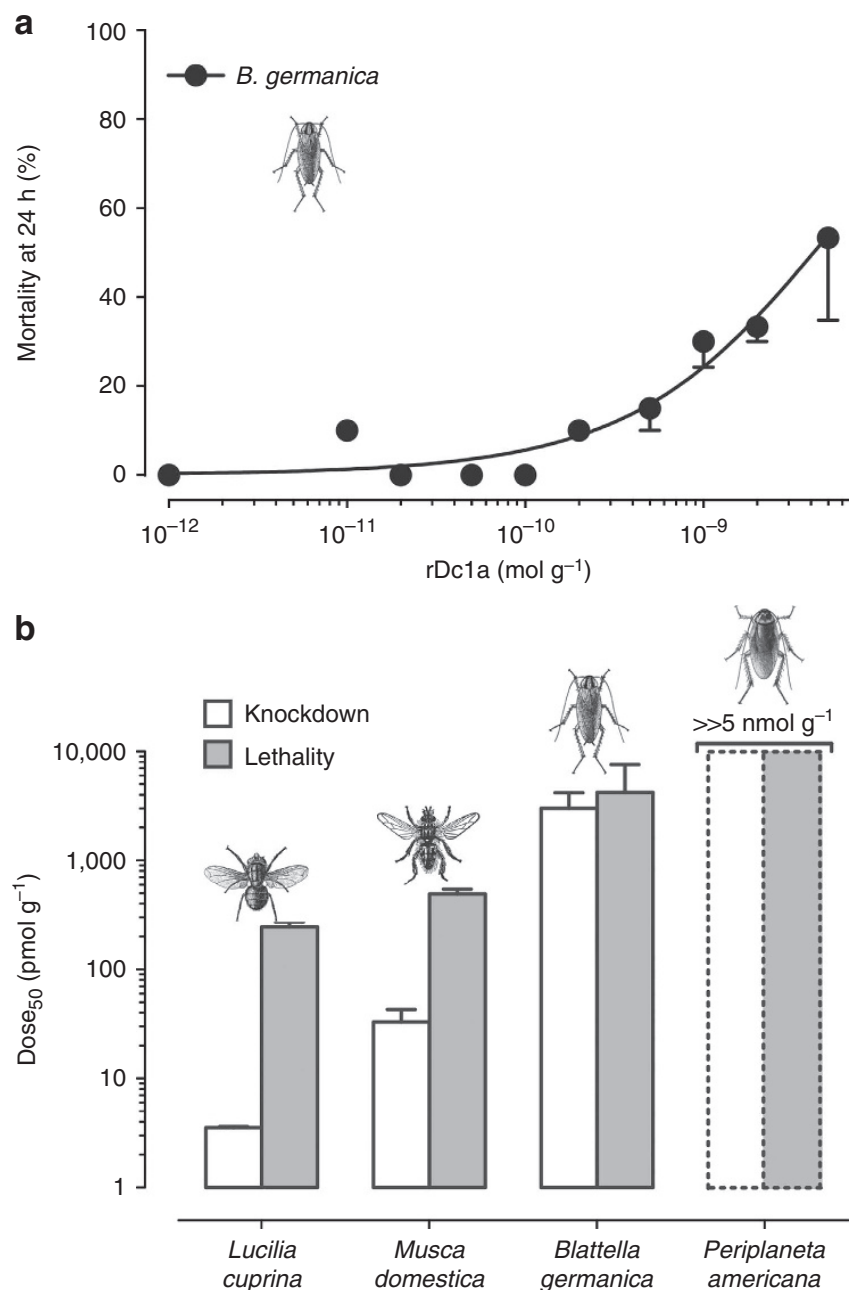

Figure 5 | Acute toxicity of rDc1a in two cockroach families.

(a) Dose-response curve for lethal effects of rDcla determined $24 \mathrm{~h}$ after injection into German cockroaches (B. germanica; family Blattellidae, closed circles). Data were fitted according to Equation 5 in Methods and represent mean \pm s.e.m. of three independent experiments. (b) Comparison of the $\mathrm{KD}_{50}$ (open columns) and $\mathrm{LD}_{50}$ (grey columns) doses at $24 \mathrm{~h}$ following injection of rDcla in L. cuprina, M. domestica and B. germanica. Note: doses up to $5 \mathrm{nmol} \mathrm{g}^{-1}$ failed to produce any signs of knockdown or lethality up to $72 \mathrm{~h}$ post injection in American cockroaches (Periplaneta americana; family Blattidae). Data represent mean \pm s.e.m. of three independent experiments.

rDcla was no longer sufficient to open $\mathrm{BgNa}_{\mathrm{v}} 1^{\mathrm{YE}}$ whereas this concentration generated large inward sodium currents when applied to WT channels (Fig. 6c, inset). When surveying higher concentrations of rDcla, it becomes clear that concentrations of more than $1 \mu \mathrm{M}$ are required to achieve a potentiation with $\mathrm{BgNa}_{\mathrm{v}} 1^{\mathrm{YE}}$ that is comparable to the WT channel $\left(\mathrm{EC}_{50} \sim 65 \mathrm{nM}\right.$; Fig. $\left.6 \mathrm{c}\right)$. Although we cannot exclude the possibility that $\mathrm{rDcla}$ interacts with other $\mathrm{PaNa}_{\mathrm{v}} 1$ domains at such concentrations, administering high doses of the toxin is indeed mildly toxic to $P$. americana (Fig. 5a,b). Thus, our mutagenesis experiments have uncovered a novel region within insect $\mathrm{Na}_{\mathrm{v}}$ channels that helps determine their sensitivity to spider toxins. This locus contributes to the drastically reduced sensitivity of the American cockroach to rDcla from the venom of the desert bush spider whereas its German counterpart is highly susceptible. 

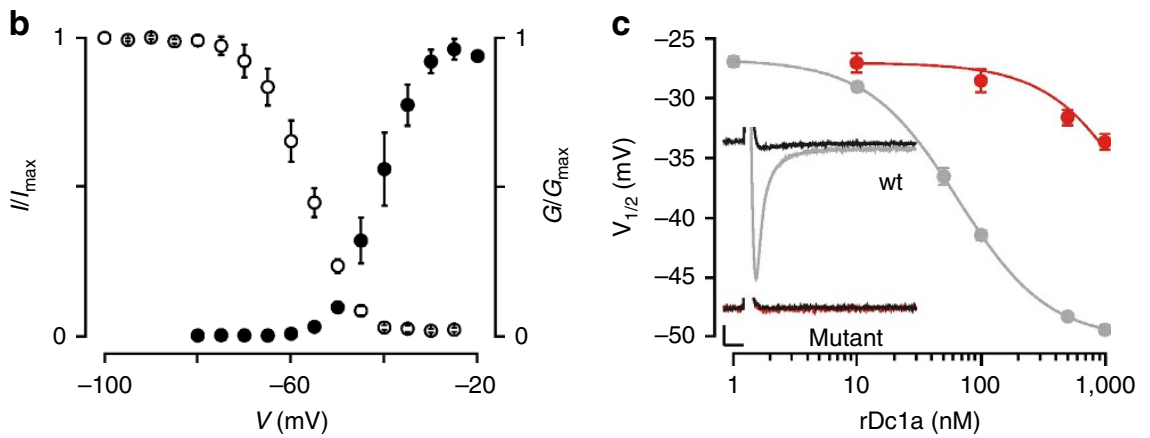

Figure 6 | Residues outside of the DII paddle motif contribute to rDc1a binding. (a) Sequence alignment of the DII S1-S2 regions of BgNa 1 and PaNa 1 (See Supplementary Fig. 4 for more details). In the extracellular loop connecting S1 to S2, all residues are identical except the H805Y and D812E substitutions (grey background). The T797M substitution within S1 is unlikely to be toxin-accessible. (b) Gating properties of the mutant BgNav ${ }^{Y}{ }^{\mathrm{E}}$ channel. Shown are the normalized deduced conductance $(G)$-voltage (filled circles) $\left(G / G_{\max }\right)$ and steady-state inactivation (open circles; $\left.I / I_{\max }\right)$ relationships. Descriptive values can be found in the Results section. Currents were elicited by $5 \mathrm{mV}$ step depolarizations from a holding voltage of $-90 \mathrm{mV}$ or $-100 \mathrm{mV}$, respectively. $n=3-5$, and error bars represent s.e.m. (c) Affinity measure for rDcla interaction with $\mathrm{BgNa}_{\mathrm{v}} 1 \mathrm{YE}$ (red) compared with WT BgNa 1 (grey). Concentration dependence for toxin-induced current potentiation (as determined by shifts in $V_{1 / 2}$ ) is shown. It is clear that alterations in channel opening on rDcla exposure are less pronounced with the $\mathrm{BgNa}_{\mathrm{v}} 1 \mathrm{YE}$ mutant when compared with $\mathrm{WT} \mathrm{BgNa}_{\mathrm{v}} 1 . n=5$ and error bars represent s.e.m. Inset shows premature channel opening after addition of $100 \mathrm{nM}$ rDcla to WT BgNa 1 (grey) whereas $\mathrm{BgNa}_{\mathrm{v}}{ }^{\mathrm{YE}}$ is not yet affected (red).

Current traces were evoked by a 50 -ms depolarization to $-55 \mathrm{mV}$ from a holding potential of $-90 \mathrm{mV}$.

\section{Discussion}

The initial goal of this study was to explore the mechanism underlying the efficacy of Dcla, a potent insecticidal peptide toxin produced by desert bush spiders. To this end, we first produced recombinant $\mathrm{rDcla}$ and determined its solution structure using heteronuclear NMR (Figs 1 and 2). Next, we tested rDcla on the heterologously expressed German cockroach channel $\mathrm{BgNa}_{\mathrm{v}} 1$ and discovered that the toxin dramatically promotes channel opening (Fig. 3). By taking advantage of the portable nature of S3b-S4 paddle motifs within voltage-sensing domains $s^{3,4,7,38}$, we demonstrated that such motifs also exist in each of the four voltage-sensing domains of $\mathrm{BgNa}_{\mathrm{v}} 1$, and that rDcla selectively interacts with the paddle motif in domain II, a feature that it shares with an extensive list of animal toxins that target this particular paddle motif ${ }^{3,4,12,55,56}$, albeit with a high degree of insect selectivity (Fig. 4). Remarkably, our insect assays revealed that German cockroaches are highly susceptible to rDcla whereas the closely related American cockroach is virtually insensitive despite the fact that the domain II paddle motif in $\mathrm{BgNa}_{\mathrm{v}} 1$ is identical to that in $\mathrm{PaNa}_{\mathrm{v}} 1$ (Fig. 5; Supplementary Fig. 4). To elucidate the machinery responsible for this discrepancy, we mutated two residues in the S1-S2 loop that differ between $\mathrm{BgNa}_{\mathrm{v}} 1$ and $\mathrm{PaNa}_{\mathrm{v}} 1$ (His805 and Asp812) and found that the susceptibility of the resulting $\mathrm{BgNa}_{\mathrm{v}} 1^{\mathrm{YE}}$ construct to $\mathrm{rDcla}$ is dramatically reduced (Fig. 6). Interestingly, mammalian $\mathrm{Na}_{\mathrm{v}}$ channel isoforms possess a Tyr and Ser at the corresponding positions, which presumably contributes to their insensitivity to rDcla; however, their domain II paddle motif differs as well (Supplementary Fig. 4).

It is interesting to consider potential mechanisms that may underlie the insect-family specificity of rDcla. For example, the $\beta 3-\beta 4$ hairpin (Fig. 2b) often houses the pharmacophore in spider ICK toxins that target voltage-gated ion channels ${ }^{57}$, but the unusual architecture of rDcla (Fig. 2c) and its unique ability to dramatically promote opening of insect $\mathrm{Na}_{\mathrm{v}}$ channels (Fig. 3) suggests that it might interact with the voltage sensors of these channels in a unique manner. As such, the domain II S1-S2 loop may play a role in positioning the toxin into a water-filled cavity adjacent to the $S 3-S 4$ paddle motif ${ }^{58}$, thereby placing particular toxin residues in strategic positions to stabilize the domain II voltage sensor in an activated position. This hypothesis is strengthened by the observation that the substitution of two residues in the domain II S1-S2 loop within mammalian $\mathrm{Na}_{\mathrm{v}} 1.2$ channels decreases sensitivity to the functionally related $\beta$-scorpion toxin CssIV by a factor of four ${ }^{59}$. Another possible mechanism is that rDcla binding to the domain II S1-S2 loop in $\mathrm{BgNa}_{\mathrm{v}} 1$ allosterically influences channel opening. Such a hypothesis was postulated when a domain III S1 splice variant of $\mathrm{BgNa}_{\mathrm{v}} 1$ revealed an increased susceptibility to the insectselective $\beta$-scorpion toxin $\mathrm{Lqh}_{-\mathrm{dprIT}_{3}}$ (ref. 60). However, one caveat is that a depolarizing prepulse is needed to potentiate the maximal effect of CssIV and Lqh-dprIT 3 (refs 49,50). Similar to the structurally unrelated spider toxin Magi5 which activates rat $\mathrm{Na}_{\mathrm{v}} 1.2$ channels by binding to the domain II voltage sensor ${ }^{61}$, rDcla does not require such a prepulse.

In summary, the current study provides a molecular explanation for the remarkable insect selectivity of Dcla, the most potent insecticidal toxin identified in the venom of the desert bush spider. Moreover, we have uncovered a novel toxin receptor site within insect $\mathrm{Na}_{\mathrm{v}}$ channels that provides a new framework for the design of molecules capable of targeting specific insect families. This knowledge may be used in the future to develop insecticides that target specific insect pests without affecting beneficial insects or endangering human health.

\section{Methods}

Chemicals. All chemicals were purchased from Sigma-Aldrich Australia (Castle Hill, NSW, Australia), Sigma-Aldrich USA (St Louis, MO, USA), or Merck Chemicals (Kilsyth, Victoria, Australia) with the exception of IPTG and streptomycin (Life Technologies, Victoria, Australia), tetrodotoxin (Alomone Labs, Israel) and high-performance liquid chromatography (HPLC)-grade acetonitrile (RCI Labscan, Bangkok, Thailand). ${ }^{13} \mathrm{C}_{6}$-glucose and ${ }^{15} \mathrm{NH}_{4} \mathrm{Cl}$ were from Sigma-Aldrich Australia. Recombinant $\mathrm{His}_{6}$-TEV protease (EC 3.4.22.44) was produced in-house using a published protocol ${ }^{62}$

Production of recombinant rDc1a. A synthetic gene encoding Dcla, with codons optimized for expression in Escherichia coli, was produced and cloned into a variant of the pLIC-MBP expression vector by GeneArt (Invitrogen, Regensburg, Germany). This vector (pLIC-NSB3) encodes a MalE signal sequence for periplasmic export, a $\mathrm{His}_{6}$ tag for affinity purification, a maltose-binding protein 
(MBP) fusion tag to aid solubility, and a tobacco etch virus (TEV) protease recognition site directly preceding the codon-optimized Dcla gene ${ }^{23}$. The plasmid encoding Dc1a was transformed into E. coli strain BL21( $(\lambda \mathrm{DE} 3)$ for recombinant toxin production. Protein expression and purification were performed as described previously ${ }^{30}$ with minor modifications. In summary, cultures were grown in LuriaBertani broth at $37^{\circ} \mathrm{C}$ with shaking. Toxin gene expression was induced with $500 \mu \mathrm{M}$ IPTG at an $\mathrm{OD}_{600}$ of $1.0-1.1$, then cells were grown at $20^{\circ} \mathrm{C}$ for a further $12 \mathrm{~h}$ before collecting by centrifugation for $15 \mathrm{~min}$ at $10,500 \mathrm{~g}$. For production of uniformly ${ }^{13} \mathrm{C} /{ }^{15} \mathrm{~N}$-labelled rDcla, cultures were grown in minimal medium supplemented with ${ }^{13} \mathrm{C}_{6}$-glucose and ${ }^{15} \mathrm{NH}_{4} \mathrm{Cl}$ as the sole carbon and nitrogen sources, respectively. The $\mathrm{His}_{6}$-MBP-toxin fusion protein was extracted from the bacterial periplasm by cell disruption at $27 \mathrm{kPa}$ (TS Series Cell Disrupter, Constant Systems Ltd, Northants, UK), and then captured by passing the extract (buffered in $40 \mathrm{mM}$ Tris, $450 \mathrm{mM} \mathrm{NaCl}, \mathrm{pH}$ 8.0) over Ni-NTA Superflow resin (Qiagen, Chadstone, Australia). Proteins bound non-specifically were removed by washing with $10 \mathrm{mM}$ imidazole then the fusion protein was eluted with $600 \mathrm{mM}$ imidazole. The eluted fusion protein was concentrated to $10 \mathrm{ml}$ and the buffer was exchanged to remove imidazole. Reduced and oxidized glutathione were then added to a final concentration of $0.6 \mathrm{mM}$ and $0.4 \mathrm{mM}$, respectively, to maintain TEV protease activity and promote folding of the protein. Approximately, $100 \mu \mathrm{g}$ of $\mathrm{His}_{6}$-tagged TEV protease was added per $\mathrm{mg}$ of $\mathrm{rDcla}$, then the cleavage reaction was allowed to proceed at room temperature for $12 \mathrm{~h}$. The cleaved $\mathrm{His}_{6}-\mathrm{MBP}$ and $\mathrm{His}_{6}$-TEV were precipitated by addition of $1 \%$ trifluoroacetic acid (TFA), then the sample was centrifuged at $16,000 \mathrm{~g}$. The supernatant was filtered using a $0.45-\mu \mathrm{m}$ syringe filter (Millipore, MA, USA) and subjected to further purification using RP-HPLC. RP-HPLC was performed on a Vydac C18 column $(250 \times 4.6 \mathrm{~mm}$, particle size $5 \mu \mathrm{m})$ using a flow rate of $1 \mathrm{ml} \mathrm{min}^{-1}$ and a gradient of $20-45 \%$ Solvent B $(0.043 \%$ TFA in $90 \%$ acetonitrile) in Solvent A (0.05\% TFA in water) over $30 \mathrm{~min}$. rDcla contains a non-native $\mathrm{N}$-terminal serine residue (a vestige of the TEV protease cleavage site), making it one residue longer than native Dcla.

Mass spectrometry. Toxin masses were confirmed by MALDI-TOF mass spectrometry using a Model 4700 Proteomics Bioanalyser (Applied Biosystems, CA, USA). RP-HPLC fractions were mixed ( $1: 1 \mathrm{v}$-v) with $\alpha$-cyano- 4 hydroxycinnamic acid matrix $\left(5 \mathrm{mg} \mathrm{ml}^{-1}\right.$ in $50 / 50$ acetonitrile $\left./ \mathrm{H}_{2} \mathrm{O}\right)$ and MALDI-TOF spectra were acquired in positive reflector mode. All reported masses are for monoisotopic $[\mathrm{M}+\mathrm{H}]^{+}$ions.

Structure determination. Several buffer conditions were screened to optimize quality of NMR data recorded for rDcla, including $20 \mathrm{mM}$ phosphate buffer, $\mathrm{pH}$ 6.0; $20 \mathrm{mM}$ MES buffer, $\mathrm{pH} 6.0$ and $20 \mathrm{mM}$ acetate buffer $\mathrm{pH}$ 5.0. Initial buffer screening revealed the acetate buffer, $\mathrm{pH} 5.0$ was optimal for acquisition of NMR data. Recombinant ${ }^{15} \mathrm{~N} /{ }^{13} \mathrm{C}$-labelled rDcla was dissolved in $20 \mathrm{mM}$ acetate buffer, pH 5.0 to a final concentration of $350 \mu \mathrm{M} .5 \%{ }^{2} \mathrm{H}_{2} \mathrm{O}$ was added, then the sample was filtered using a low-protein-binding Ultrafree-MC centrifugal filter $(0.22 \mu \mathrm{m}$ pore size; Millipore, MA, USA) and $300 \mu \mathrm{l}$ was added to a susceptibility matched $5 \mathrm{~mm}$ outer-diameter microtube (Shigemi Inc., Japan). NMR data were acquired at $25^{\circ} \mathrm{C}$ using a $900 \mathrm{MHz}$ NMR spectrometer (Bruker BioSpin, Germany) equipped with a cryogenically cooled probe. $3 \mathrm{D}$ and $4 \mathrm{D}$ data used for resonance assignments were acquired using non-uniform sampling. Sampling schedules that approximated the signal decay in each indirect dimension were generated using sched $3 \mathrm{D}^{26}$. Non-uniform sampling data were processed using the Rowland NMR toolkit (www.rowland.org/rnmrtk/toolkit.html) and maximum entropy parameters were automatically selected as previously described ${ }^{63} \cdot{ }^{13} \mathrm{C}$ - and ${ }^{15} \mathrm{~N}$-edited HSQC-NOESY (mixing time of $200 \mathrm{~ms}$ ) experiments were acquired using uniform sampling. All experiments were acquired in $\mathrm{H}_{2} \mathrm{O}$ containing $5 \%{ }^{2} \mathrm{H}_{2} \mathrm{O}$. Dihedral angles $(\phi, \psi)$ were derived from TALOS + chemical shift analysis ${ }^{64}$ and the restraint range for structure calculations was set to twice the estimated s.d. The Gly9-Pro10 and Arg36-Pro37 peptide bond was determined to be in the trans conformation on the basis of characteristic NOEs and the $\mathrm{C}_{\alpha}$ and $\mathrm{C}_{\beta}$ chemical shifts of Pro residues. NOESY spectra were manually peak picked and integrated, then peak lists were automatically assigned, distance restraints extracted and an ensemble of structures calculated using the torsion angle dynamics package CYANA 3.0 (ref. 25). The tolerances used for CYANA 3.0 were 0.025 p.p.m. in the direct ${ }^{1} \mathrm{H}$ dimension, 0.03 p.p.m. in the indirect ${ }^{1} \mathrm{H}$ dimension and 0.3 p.p.m. for the heteronucleus $\left({ }^{13} \mathrm{C} /{ }^{15} \mathrm{~N}\right)$. During the automated NOESY assignment/structure calculation process, CYANA assigned $92 \%$ of all NOESY crosspeaks $(2,271$ out of 2,469$)$.

Insecticidal assays. rDcla was dissolved in insect saline and injected into the ventro-lateral thoracic region of adult sheep blowflies (Lucilia cuprina;), adult houseflies ( $M$. domestica), adult American cockroaches (Periplaneta americana) and adult German cockroaches (Blattella germanica) ${ }^{65}$. Injections were made using a $1.0 \mathrm{ml}$ Terumo Insulin syringe (B-D Ultra-Fine, Terumo Medical Corporation, Maryland, USA) with a fixed $29 \mathrm{G}$ needle fitted to an Arnold hand micro-applicator (Burkard Manufacturing Co. Ltd., England). A maximum volume of $2 \mu \mathrm{l}$ was injected per L. cuprina, M. domestica and B. germanica and $5 \mu \mathrm{l}$ for the larger $P$. americana. Thereafter, flies were individually housed in 2-ml tubes and provided with $10 \%$ sucrose while cockroaches were housed in closed Petri dishes and provided with dry food and water. The paralytic activity was then determined over a 24-h period. For each acute toxicity assay up to fourteen doses of $\operatorname{rDcla}(n=10$ insects per dose) and the appropriate control (insect saline; $n=10$ insects) were used. The assay was repeated three times. Median knockdown $\left(\mathrm{KD}_{50}\right)$ and median lethal $\left(\mathrm{LD}_{50}\right)$ doses were calculated as described previously ${ }^{66}$ and averaged to produce $\mathrm{KD}_{50}$ and $\mathrm{LD}_{50}$ values.

Electrophysiological measurements on DUM neurons. DUM neurons were isolated from unsexed adult American cockroaches (P. americana) as described previously ${ }^{30}$. Briefly, terminal abdominal ganglia were removed and placed in normal insect saline (NIS) containing (in $\mathrm{mM}$ ): $\mathrm{NaCl} 180, \mathrm{KCl} 3.1$, $N$-hydroxyethylpiperazine- $N$-ethanesulfonic acid (HEPES) 10 and D-glucose 20. Ganglia were then incubated in $1 \mathrm{mg} \mathrm{ml}^{-1}$ collagenase (type IA) for $40 \mathrm{~min}$ at $29^{\circ} \mathrm{C}$. Following enzymatic treatment, ganglia were washed three times in NIS and triturated through a fire-polished Pasteur pipette. The resultant cell suspension was then distributed onto $12-\mathrm{mm}$ diameter glass coverslips pre-coated with $2 \mathrm{mg} \mathrm{ml}^{-1}$ concanavalin A (type IV). DUM neurons were maintained in NIS supplemented with $5 \mathrm{mM} \mathrm{CaCl}_{2}, 4 \mathrm{mM} \mathrm{MgCl}_{2}, 5 \%$ foetal bovine serum and $1 \%$ penicillin and streptomycin (Life Technologies, Victoria, Australia), and maintained at $29^{\circ} \mathrm{C}$, $100 \%$ humidity. Ionic currents were recorded in voltage-clamp mode using the whole-cell patch-clamp technique employing version 10.2 of the pCLAMP data acquisition system (Molecular Devices, Sunnyvale, CA). Data were filtered at $5-10 \mathrm{kHz}$ with a low-pass Bessel filter with leakage and capacitive currents subtracted using $P$ - $P / 4$ procedures. Digital sampling rates were set between 15 and $25 \mathrm{kHz}$ depending on the length of the protocol. Single-use $0.8-2.5 \mathrm{M} \Omega$ electrodes were pulled from borosilicate glass and fire-polished prior to current recordings. Liquid junction potentials were calculated using JPCALC, and all data were compensated for these values. Cells were bathed in external solution through a continuous pressurized perfusion system at $1 \mathrm{ml} \mathrm{min}^{-1}$, while toxin solutions were introduced via direct pressurized application via a perfusion needle at $\sim 50 \mu \mathrm{lmin}^{-1}$ (Automate Scientific, San Francisco, CA). Control data were not acquired until at least $20 \mathrm{~min}$ after whole-cell configuration was achieved to eliminate the influence of initially fast time-dependent shifts in steady-state inactivation resulting in $\mathrm{Na}_{\mathrm{V}}$ channel current $\left(I_{\mathrm{Na}}\right)$ rundown. All experiments were performed at ambient temperature $\left(20-23^{\circ} \mathrm{C}\right)$. To record $I_{\mathrm{Na}}$, the external bath solution contained (in $\mathrm{mM}$ ): $\mathrm{NaCl} 80, \mathrm{CsCl} 5, \mathrm{CaCl}_{2} 1.8$, tetraethylammonium chloride 50, 4-aminopyridine 5, HEPES $10, \mathrm{NiCl}_{2} 0.1$, and $\mathrm{CdCl}_{2} 1$, adjusted to $\mathrm{pH}$ 7.4 with $1 \mathrm{M} \mathrm{NaOH}$. The pipette solution contained (in $\mathrm{mM}$ ): $\mathrm{NaCl} 34, \mathrm{CsF} 135$, $\mathrm{MgCl}_{2}$ 1, HEPES 10, ethylene glycol-bis(2-aminoethylether)- $N, N, N^{\prime}, N^{\prime}$-tetraacetic acid 5, and ATP- $\mathrm{Na}_{2} 3$, adjusted to $\mathrm{pH} 7.4$ with $1 \mathrm{M} \mathrm{CsOH}$. To eliminate any influence of differences in osmotic pressure, all internal and external solutions were adjusted with sucrose to $400 \pm 5$ mOsmoll ${ }^{-1}$. Experiments were rejected if there were large leak currents or currents showed signs of poor space clamping.

Off-line data analysis was performed using Axograph X version 1.3 or Clampfit 10 (Molecular Devices, USA). Voltage-activation relationships were obtained by measuring steady-state currents elicited by stepwise depolarizations of $5-10 \mathrm{mV}$ from a holding potential of $-90 \mathrm{mV}$ and calculating peak conductance $\left(G_{\mathrm{Na}}\right)$ using the following equation: $G=I_{\mathrm{Na}} /\left(V_{\mathrm{m}}-E_{\text {rev }}\right)$ where $G$ is peak conductance, $I_{\mathrm{Na}}$ is peak inward sodium current, $V_{\mathrm{m}}$ is the test potential and $E_{\text {rev }}$ is the reversal potential. Reversal potentials were individually estimated for each data set ${ }^{67}$ by fitting the $I_{\mathrm{Na}}-V$ data with the following equation: $I_{\mathrm{Na}}=[1+\exp (-0.03937 \times \mathrm{z}$ $\left.\left.\times\left(V_{\mathrm{m}}-\mathrm{V}_{1 / 2}\right)\right)\right]^{-1} \times g \times\left(V_{\mathrm{m}}-V_{\text {rev }}\right)$ where $z$ is the apparent gating charge, $g$ is a factor related to the number of channels contributing to the macroscopic wholecell $I_{\mathrm{Na}}, V_{\mathrm{m}}$ is equal to the voltage potential of the pulse, and $\mathrm{V}_{1 / 2}$ is the voltage at half-maximal activation. The normalized conductance was fitted to a two-state Boltzmann function of the form: $G / G_{\max }=1 /\left(1+\exp \left(\left(-0.3937 \times \mathrm{z} \times\left(V_{\mathrm{m}}-V_{1 / 2}\right)\right)\right)\right.$ where $G, \mathrm{z}, V_{\mathrm{m}}$ and $V_{1 / 2}$ have the same meaning. The voltage dependence of steady-state $\mathrm{Na}_{\mathrm{v}}$ channel inactivation $\left(h_{\infty} / V\right)$ data were normalized to the maximum peak current in the control or maximum peak current and fitted using the following Boltzmann equation: $h_{\infty}=\mathrm{A} /\left(1+\exp \left(\left(V_{\mathrm{m}}-V_{1 / 2}\right) / k\right)\right)$ where $\mathrm{A}$ is the fraction of control maximal peak $I_{\mathrm{Na}}$ (value of 1.0 under control conditions), $V_{1 / 2}$ is the midpoint of steady-state inactivation, $k$ is the slope factor and $V_{\mathrm{m}}$ is the prepulse voltage. The rate of recovery from fast inactivation data were fitted to the following single-exponential function: $I / I_{\max }=1-\exp (-\tau / t)$ where $\tau$ is the time constant of current recovery. Dose-response curves to determine $\mathrm{LD}_{50}$ and $\mathrm{KD}_{50}$ values were fitted using the following form of the logistic equation: $y=1 /(1+[x] /$ Dose $\left._{50}\right)^{n \mathrm{H}}$ where $x$ is the toxin dose, $n_{\mathrm{H}}$ the Hill coefficient (slope parameter) and Dose $_{50}$ is the median inhibitory dose causing lethality $\left(\mathrm{LD}_{50}\right)$ or knockdown $\left(\mathrm{KD}_{50}\right)$. Non-linear curve-fitting of data were performed using GraphPad Prism version 6.00c for Macintosh (GraphPad Software, San Diego) or Origin 8 (OriginLab, MA, USA). Comparisons of two sample means were made using a paired Student's $t$-test and differences were considered to be significant if $P<0.05$. All data are presented as mean \pm s.e.m. of $n$ independent experiments.

Electrophysiological measurements on oocytes. Chimeras and channel mutants were generated using sequential PCRs with $\mathrm{K}_{\mathrm{v}} 2.1 \Delta 7$ (ref. 68) and $\mathrm{BgNa}_{\mathrm{v}} 1$ (ref. 21) as templates. The Kv2.1 $\Delta 7$ construct contains seven point mutations in the outer vestibule, rendering the channel sensitive to agitoxin-2. The DNA sequence of all constructs and mutants was confirmed by automated DNA sequencing and cRNA was synthesized using T7 polymerase (mMessage mMachine kit, Life Technologies, 
USA) after linearizing the DNA with appropriate restriction enzymes. Channel constructs including $\mathrm{hNa}_{\mathrm{v}} 1.1-\mathrm{hNa}_{\mathrm{v}} 1.7$ and hERG were expressed in Xenopus oocytes by themselves or, in the case of $\mathrm{BgNa}_{\mathrm{v}} 1$, together with the TipE subunit ${ }^{69}$ (1:5 molar ratio), and studied following 1-2 days incubation after cRNA injection (incubated at $17^{\circ} \mathrm{C}$ in $96 \mathrm{mM} \mathrm{NaCl}, 2 \mathrm{mM} \mathrm{KCl}, 5 \mathrm{mM}$ HEPES, $1 \mathrm{mM} \mathrm{MgCl}$ and $1.8 \mathrm{mM} \mathrm{CaCl}_{2}, 50 \mu \mathrm{g} \mathrm{ml}^{-1}$ gentamycin, $\mathrm{pH} 7.6$ with $\mathrm{NaOH}$ ) using two-electrode voltage-clamp recording techniques (OC-725C, Warner Instruments, USA) with a $150-\mu \mathrm{l}$ recording chamber. Data were filtered at $4 \mathrm{kHz}$ and digitized at $20 \mathrm{kHz}$ using pClamp software (Molecular Devices, USA). Microelectrode resistances were 0.5-1 $\mathrm{M} \Omega$ when filled with $3 \mathrm{M} \mathrm{KCl}$. For most $\mathrm{K}_{\mathrm{v}}$ channel experiments, the external recording solution contained (in $\mathrm{mM}$ ): $50 \mathrm{KCl}, 50 \mathrm{NaCl}, 5$ HEPES, $1 \mathrm{MgCl}_{2}, 0.3$ $\mathrm{CaCl}_{2}$, pH 7.6 with $\mathrm{NaOH}$. For $\mathrm{Na}_{\mathrm{v}}$ channel experiments, the external recording solution contained (in $\mathrm{mM}$ ): $96 \mathrm{NaCl}, 2 \mathrm{KCl}, 5 \mathrm{HEPES}, 1 \mathrm{MgCl}_{2}$ and $1.8 \mathrm{CaCl}_{2}, \mathrm{pH}$ 7.6 with $\mathrm{NaOH}$. All experiments were performed at room temperature $\left(\sim 22^{\circ} \mathrm{C}\right)$. Leak and background conductances, identified by blocking the channel with agitoxin-2 (Alomone labs) or tetrodotoxin, were subtracted for most of the $\mathrm{K}_{\mathrm{v}}$ or $\mathrm{BgNa}_{\mathrm{v}} 1$ currents shown.

Voltage-activation relationships were obtained by measuring tail currents for $\mathrm{K}_{\mathrm{v}}$ channels or steady-state currents and calculating conductance for $\mathrm{Na}_{\mathrm{v}}$ channels. Protocols for other measurements are described in the figure legends. After addition of the toxin to the recording chamber, the equilibration between the toxin and the channel was monitored using weak depolarizations elicited at 5-s intervals. For all channels, we recorded voltage-activation relationships in the absence and presence of toxin. Off-line data analysis was performed using Clampfit 10 (Molecular Devices, USA), Origin 8.0 (Originlab) and Microsoft Solver (Microsoft Excel).

\section{References}

1. King, G. F., Escoubas, P. \& Nicholson, G. M. Peptide toxins that selectively target insect $\mathrm{Na}_{\mathrm{V}}$ and $\mathrm{Ca}_{\mathrm{V}}$ channels. Channels 2, 100-116 (2008).

2. Hille, B. Ion Channels of Excitable Membranes 3rd edn (Sinauer Associates, Inc., 2001).

3. Bosmans, F., Martin-Eauclaire, M. F. \& Swartz, K. J. Deconstructing voltage sensor function and pharmacology in sodium channels. Nature 456, 202-208 (2008)

4. Bosmans, F., Puopolo, M., Martin-Eauclaire, M. F., Bean, B. P. \& Swartz, K. J. Functional properties and toxin pharmacology of a dorsal root ganglion sodium channel viewed through its voltage sensors. J. Gen. Physiol. 138, 59-72 (2011).

5. Payandeh, J., Scheuer, T., Zheng, N. \& Catterall, W. A. The crystal structure of a voltage-gated sodium channel. Nature 475, 353-358 (2011).

6. Zhang, X. et al. Crystal structure of an orthologue of the $\mathrm{NaChBac}$ voltagegated sodium channel. Nature 486, 130-134 (2012).

7. Milescu, M. et al. Interactions between lipids and voltage sensor paddles detected with tarantula toxins. Nat. Struct. Mol. Biol. 16, 1080-1085 (2009).

8. Dong, K. Insect sodium channels and insecticide resistance. Invert. Neurosci. 7, 17-30 (2007).

9. Soderlund, D. M. Molecular mechanisms of pyrethroid insecticide neurotoxicity: recent advances. Arch. Toxicol. 86, 165-181 (2012).

10. Tan, J. \& Soderlund, D. M. Divergent actions of the pyrethroid insecticides S-bioallethrin, tefluthrin, and deltamethrin on rat $\mathrm{Na}_{\mathrm{v}} 1.6$ sodium channels. Toxicol. Appl. Pharmacol. 247, 229-237 (2010).

11. Zakon, H. H. Adaptive evolution of voltage-gated sodium channels: the first 800 million years. Proc. Natl Acad. Sci. USA 109, 10619-10625 (2012).

12. Bosmans, F. \& Swartz, K. J. Targeting voltage sensors in sodium channels with spider toxins. Trends Pharmacol. Sci. 31, 175-182 (2010).

13. Fry, B. G. et al. The toxicogenomic multiverse: convergent recruitment of proteins into animal venoms. Annu. Rev. Genomics Hum. Genet. 10, 483-511 (2009).

14. Klint, J. K. et al. Spider-venom peptides that target voltage-gated sodium channels: pharmacological tools and potential therapeutic leads. Toxicon $\mathbf{6 0}$, 478-491 (2012)

15. King, G. F. \& Hardy, M. C. Spider-venom peptides: structure, pharmacology, and potential for control of insect pests. Annu. Rev. Entomol. 58, 475-496 (2013).

16. Boulton, A. M. \& Polis, G. A. Phenology and life history of the desert spider, Diguetia majavea. J. Arachnol. 27, 513-521 (1999).

17. Gertsch, W. J. The Spider Family Diguetidae (American Museum Novitates No. 1904, 1985)

18. King, G. F., Gentz, M. C., Escoubas, P. \& Nicholson, G. M. A rational nomenclature for naming peptide toxins from spiders and other venomous animals. Toxicon 52, 264-276 (2008).

19. Krapcho, K. J., Kral, Jr R. M., Vanwagenen, B. C., Eppler, K. G. \& Morgan, T. K. Characterization and cloning of insecticidal peptides from the primitive weaving spider Diguetia canities. Insect Biochem. Mol. Biol. 25, 991-1000 (1995).

20. Bloomquist, J. R., Kinne, L. P., Deutsch, V. \& Simpson, S. F. Mode of action of an insecticidal peptide toxin from the venom of a weaving spider (Diguetia canities). Toxicon 34, 1072-1075 (1996).
21. Dong, K. A single amino acid change in the para sodium channel protein is associated with knockdown-resistance (kdr) to pyrethroid insecticides in German cockroach. Insect Biochem. Mol. Biol. 27, 93-100 (1997).

22. Moignot, B., Lemaire, C., Quinchard, S., Lapied, B. \& Legros, C. The discovery of a novel sodium channel in the cockroach Periplaneta americana: evidence for an early duplication of the para-like gene. Insect Biochem. Mol. Biol. 39, 814-823 (2009)

23. Klint, J. K. et al. Production of recombinant disulfide-rich venom peptides for structural and functional analysis via expression in the periplasm of $E$. coli. PLoS ONE 8, e63865 (2013).

24. Mobli, M. \& King, G. F. NMR methods for determining disulfide-bond connectivities. Toxicon 56, 849-854 (2010).

25. Güntert, P. Automated NMR structure calculation with CYANA. Methods Mol. Biol. 278, 353-378 (2004).

26. Mobli, M., Stern, A. S., Bermel, W., King, G. F. \& Hoch, J. C. A non-uniformly sampled 4D HCC(CO)NH-TOCSY experiment processed using maximum entropy for rapid protein sidechain assignment. J. Magn. Reson. 204, 160-164 (2010).

27. Davis, I. W. et al. MolProbity: all-atom contacts and structure validation for proteins and nucleic acids. Nucleic Acids Res. 35, W375-W383 (2007).

28. Kwan, A. H., Mobli, M., Gooley, P. R., King, G. F. \& Mackay, J. P. Macromolecular NMR spectroscopy for the non-spectroscopist. FEBS J. 278, 687-703 (2011).

29. Holm, L. \& Rosenstrom, P. Dali server: conservation mapping in 3D. Nucleic Acids Res. 38, W545-W549 (2010).

30. Bende, N. S. et al. The insecticidal neurotoxin Aps III is an atypical knottin peptide that potently blocks insect voltage-gated sodium channels. Biochem. Pharmacol. 85, 1542-1554 (2013).

31. Milescu, M. et al. Tarantula toxins interact with voltage sensors within lipid membranes. J. Gen. Physiol. 130, 497-511 (2007).

32. Eberhard, W. Attack behavior of diguetid spiders and the origin of prey wrapping in spiders. Psyche 74, 173-181 (1967).

33. Liu, Z., Song, W. \& Dong, K. Persistent tetrodotoxin-sensitive sodium current resulting from U-to-C RNA editing of an insect sodium channel. Proc. Nat Acad. Sci. USA 101, 11862-11867 (2004).

34. Trudeau, M. C., Warmke, J. W., Ganetzky, B. \& Robertson, G. A. HERG, a human inward rectifier in the voltage-gated potassium channel family. Science 269, 92-95 (1995)

35. Cestele, S. et al. Structure and function of the voltage sensor of sodium channels probed by a beta-scorpion toxin. J. Biol. Chem. 281, 21332-21344 (2006).

36. Cestele, S. et al. Voltage sensor-trapping: enhanced activation of sodium channels by $\beta$-scorpion toxin bound to the S3-S4 loop in domain II. Neuron 21, 919-931 (1998).

37. Swartz, K. J. Tarantula toxins interacting with voltage sensors in potassium channels. Toxicon 49, 213-230 (2007).

38. Alabi, A. A., Bahamonde, M. I., Jung, H. J., Kim, J. I. \& Swartz, K. J. Portability of paddle motif function and pharmacology in voltage sensors. Nature $\mathbf{4 5 0}$ 370-375 (2007)

39. Long, S. B., Tao, X., Campbell, E. B. \& MacKinnon, R. Atomic structure of a voltage-dependent $\mathrm{K}^{+}$channel in a lipid membrane-like environment. Nature 450, 376-382 (2007).

40. Aggarwal, S. K. \& MacKinnon, R. Contribution of the S4 segment to gating charge in the Shaker $\mathrm{K}^{+}$channel. Neuron 16, 1169-1177 (1996).

41. Seoh, S. A., Sigg, D., Papazian, D. M. \& Bezanilla, F. Voltage-sensing residues in the S2 and S4 segments of the Shaker $\mathrm{K}^{+}$channel. Neuron 16, 1159-1167 (1996).

42. Zagotta, W. N., Hoshi, T. \& Aldrich, R. W. Shaker potassium channel gating. III: evaluation of kinetic models for activation. J. Gen. Physiol. 103, 321-362 (1994).

43. Delemotte, L., Tarek, M., Klein, M. L., Amaral, C. \& Treptow, W. Intermediate states of the Kv1.2 voltage sensor from atomistic molecular dynamics simulations. Proc. Natl Acad. Sci. USA 108, 6109-6114 (2011).

44. Jensen, M. O. et al. Mechanism of voltage gating in potassium channels. Science 336, 229-233 (2012).

45. Tao, X., Lee, A., Limapichat, W., Dougherty, D. A. \& MacKinnon, R. A gating charge transfer center in voltage sensors. Science 328, 67-73 (2010).

46. Gagnon, D. G. \& Bezanilla, F. A single charged voltage sensor is capable of gating the Shaker $\mathrm{K}^{+}$channel. J. Gen. Physiol. 133, 467-483 (2009).

47. Lacroix, J. J. et al. Intermediate state trapping of a voltage sensor. J. Gen. Physiol. 140, 635-652 (2012)

48. Buraei, Z., Anghelescu, M. \& Elmslie, K. S. Slowed N-type calcium channel $\left(\mathrm{Ca}_{\mathrm{V}} 2.2\right)$ deactivation by the cyclin-dependent kinase inhibitor roscovitine. Biophys. J. 89, 1681-1691 (2005).

49. Capes, D. L., Goldschen-Ohm, M. P., Arcisio-Miranda, M., Bezanilla, F. \& Chanda, B. Domain IV voltage-sensor movement is both sufficient and rate limiting for fast inactivation in sodium channels. J. Gen. Physiol. 142, 101-112 (2013). 
50. Chanda, B. \& Bezanilla, F. Tracking voltage-dependent conformational changes in skeletal muscle sodium channel during activation. J. Gen. Physiol. 120, 629-645 (2002).

51. Sheets, M. F., Kyle, J. W., Kallen, R. G. \& Hanck, D. A. The Na channel voltage sensor associated with inactivation is localized to the external charged residues of domain IV, S4. Biophys. J. 77, 747-757 (1999).

52. Cestele, S. et al. Scorpion $\alpha$-like toxins, toxic to both mammals and insects, differentially interact with receptor site 3 on voltage-gated sodium channels in mammals and insects. Eur. J. Neurosci. 11, 975-985 (1999).

53. Tan, J., Liu, Z., Nomura, Y., Goldin, A. L. \& Dong, K. Alternative splicing of an insect sodium channel gene generates pharmacologically distinct sodium channels. J. Neurosci. 22, 5300-5309 (2002).

54. Bourdin, C. M. et al. Intron retention in mRNA encoding ancillary subunit of insect voltage-gated sodium channel modulates channel expression, gating regulation and drug sensitivity. PLoS ONE 8, e67290 (2013).

55. Catterall, W. A. et al. Voltage-gated ion channels and gating modifier toxins. Toxicon 49, 124-141 (2007).

56. Xiao, Y., Jackson, 2nd J. O., Liang, S. \& Cummins, T. R. Common molecular determinants of tarantula huwentoxin-IV inhibition of $\mathrm{Na}^{+}$channel voltage sensors in domains II and IV. J. Biol. Chem. 286, 27301-27310 (2011).

57. Saez, N. J. et al. Spider-venom peptides as therapeutics. Toxins 2, 2851-2871 (2010).

58. Krepkiy, D. et al. Structure and hydration of membranes embedded with voltage-sensing domains. Nature 462, 473-479 (2009).

59. Zhang, J. Z. et al. Structure-function map of the receptor site for $\beta$-scorpion toxins in domain II of voltage-gated sodium channels. J. Biol. Chem. 286, 33641-33651 (2011)

60. Song, W. et al. Substitutions in the domain III voltage-sensing module enhance the sensitivity of an insect sodium channel to a scorpion $\beta$-toxin. J. Biol. Chem. 286, 15781-15788 (2011)

61. Corzo, G. et al. Distinct primary structures of the major peptide toxins from the venom of the spider Macrothele gigas that bind to sites 3 and 4 in the sodium channel. FEBS Lett. 547, 43-50 (2003).

62. Fang, L. et al. An improved strategy for high-level production of TEV protease in Escherichia coli and its purification and characterization. Protein Expr. Purif. 51, 102-109 (2007).

63. Mobli, M., Maciejewski, M. W., Gryk, M. R. \& Hoch, J. C. An automated tool for maximum entropy reconstruction of biomolecular NMR spectra. Nat. Methods 4, 467-468 (2007).

64. Shen, Y., Delaglio, F., Cornilescu, G. \& Bax, A. TALOS + : a hybrid method for predicting protein backbone torsion angles from NMR chemical shifts. J. Biomol. NMR 44, 213-223 (2009).

65. Eitan, M. et al. A scorpion venom neurotoxin paralytic to insects that affects sodium current inactivation: purification, primary structure, and mode of action. Biochemistry 29, 5941-5947 (1990).

66. Herzig, V. \& Hodgson, W. C. Neurotoxic and insecticidal properties of venom from the Australian theraphosid spider Selenotholus foelschei. Neurotoxicology 29, 471-475 (2008)
67. Zhou, W. \& Goldin, A. L. Use-dependent potentiation of the Nav1.6 sodium channel. Biophys. J. 87, 3862-3872 (2004).

68. Swartz, K. J. \& MacKinnon, R. Hanatoxin modifies the gating of a voltagedependent $\mathrm{K}^{+}$channel through multiple binding sites. Neuron 18, 665-673 (1997).

69. Feng, G., Deak, P., Chopra, M. \& Hall, L. M. Cloning and functional analysis of TipE, a novel membrane protein that enhances Drosophila para sodium channel function. Cell 82, 1001-1011 (1995).

70. Nguyen, M. N., Tan, K. P. \& Madhusudhan, M. S. CLICK-topologyindependent comparison of biomolecular 3D structures. Nucleic Acids Res. 39, W24-W28 (2011).

\section{Acknowledgements}

We would like to thank Ke Dong (Michigan State University), Kenton J Swartz (NIH), Peter Ruben (Simon Fraser University), Chris Ahern (University of Iowa), James Barrow (Johns Hopkins University/Lieber Institute for Brain Development), and Marie-France Martin-Eauclaire and Pierre E Bougis (University of Marseille) for sharing $\mathrm{BgNa}_{\mathrm{v}} 1 / \mathrm{TipE}$, $\mathrm{K}_{\mathrm{v}} 2.1, \mathrm{hNa}_{\mathrm{v}} 1.4, \mathrm{hNa}_{\mathrm{v}} 1.5$, hERG and BomIV, respectively. We thank Sandipan Chowdhury and Carlos Villalba-Galea for helpful discussions and Geoff Brown (Department of Agriculture, Fisheries and Forestry, Brisbane) for supply of blowflies Parts of the research in this publication were supported by the Australian Research Council (Discovery Grant DP130103813 to G.F.K.) and the National Institute of Neurological Disorders and Stroke (NINDS) of the National Institutes of Health (NIH) under award number R00NS073797 (F.B.).

\section{Author contributions}

N.S.B., S.D., M.M., V.H., J.G., G.M.N., G.F.K. and F.B. designed research; N.S.B., S.D., M.M., V.H., J.G., J.W., G.M.N., G.F.K. and F.B. performed research; N.S.B., S.D., M.M., V.H., G.M.N., G.F.K. and F.B. analysed data; N.S.B., S.D., M.M., V.H., G.M.N., G.F.K. and F.B. wrote the paper.

\section{Additional information}

Accession codes: Complete chemical shift assignments for rDcla have been deposited in BioMagResBank under accession code 19666.

Supplementary Information accompanies this paper at http://www.nature.com/ naturecommunications

Competing financial interests: The authors declare no competing financial interests.

Reprints and permission information is available online at http://npg.nature.com/ reprintsandpermissions/

How to cite this article: Bende, N. S. et al. A distinct sodium channel voltage-sensor locus determines insect selectivity of the spider toxin Dcla. Nat. Commun. 5:4350 doi: 10.1038/ncomms5350 (2014). 